\title{
Agôn
}

Revue des arts de la scène

Critiques | Saison 2013-2014

\section{Situation Rooms de Rimini Protokoll}

Du politique aux politesses

\section{Marion Siéfert}

\section{(2) OpenEdition}

Journals

Édition électronique

URL : http://journals.openedition.org/agon/3044

DOI : 10.4000/agon.3044

ISSN : 1961-8581

Éditeur

Association Agôn

Référence électronique

Marion Siéfert, "Situation Rooms de Rimini Protokoll », Agôn [En ligne], Critiques, mis en ligne le 20 mai 2014, consulté le 23 septembre 2020. URL : http://journals.openedition.org/agon/3044 ; DOI : https:// doi.org/10.4000/agon.3044

Ce document a été généré automatiquement le 23 septembre 2020

Association Agôn et les auteurs des articles 


\title{
Situation Rooms de Rimini Protokoll
}

\author{
Du politique aux politesses
}

\section{Marion Siéfert}

\section{RÉFÉRENCE}

Situation Rooms, présenté à la Grande Halle de La Villette, du 16 au 25 mai 2014.

1 À l'origine de Situation Rooms, dernière mise en scène du label berlinois Rimini Protokoll, il y a une photo célèbre, celle prise par le photographe Pete Souza le $1^{\mathrm{er}}$ mai 2011. Sur cette photo, prénommée The Situation Room, on peut voir Barack Obama, entouré de son équipe de sécurité nationale, assister à l'opération « Neptune's Spear » qui aura conduit à la mort d'Oussama Ben Laden. Grâce à une caméra embarquée sur le casque de l'un des membres du commando d'assaut, les dirigeants de la Maison Blanche ont pu suivre les événements en direct et vivre, selon Hilary Clinton, « les 38 minutes les plus intenses de [leur] vie ». On pourrait penser que cette photo éponyme condense les problématiques du projet de Rimini Protokoll : comment nous positionner face aux images de guerre? Quelle est leur valeur politique? Comment dépasser les images quand les médias nous demandent à tout prix de « rentrer dedans »? 


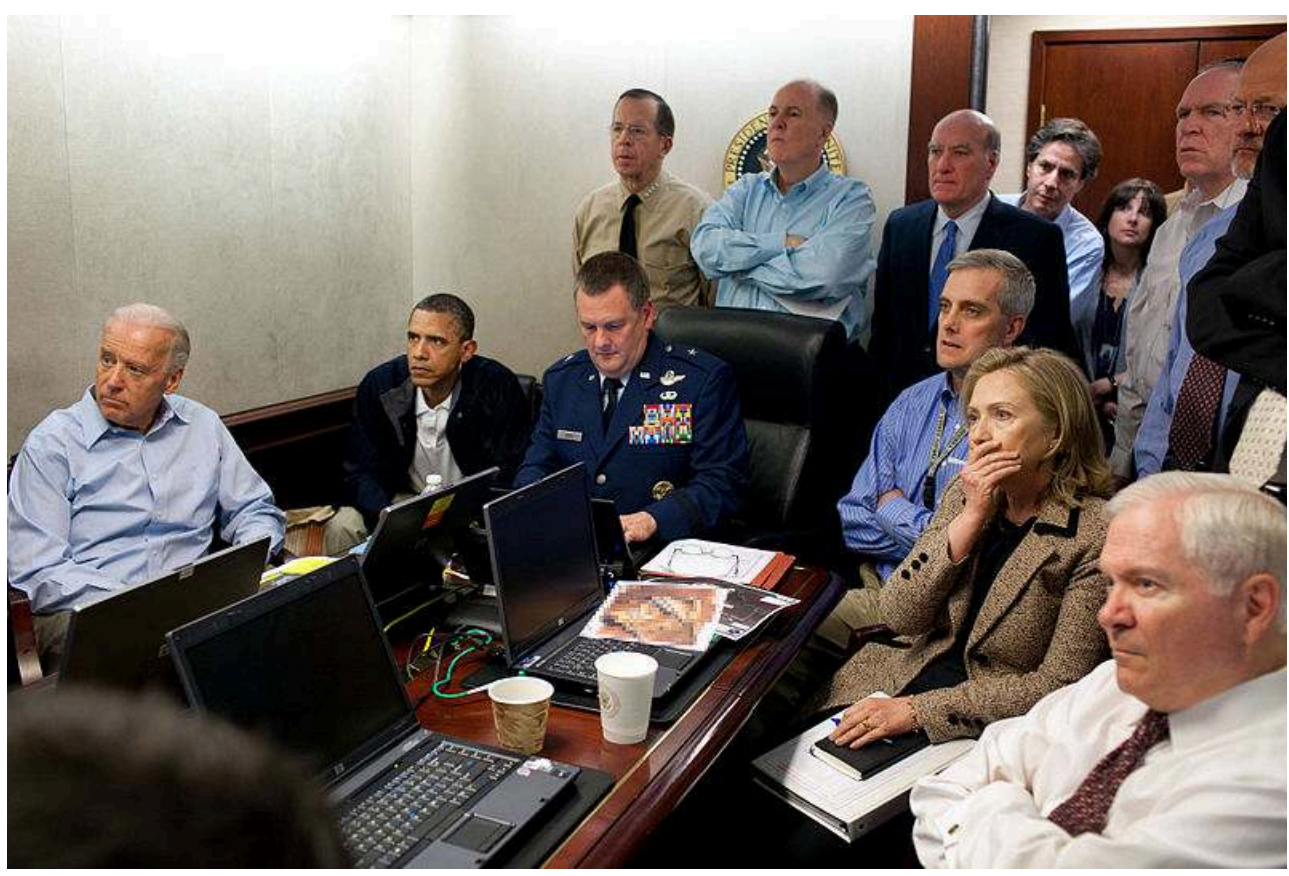

(c) Pete Souza

2 Seulement, Situation Rooms ne laisse à son spectateur ni le temps de penser ni celui de regarder, tant il le soumet à un flux continu d'informations et à un planning extrêmement minuté, duquel il ne peut déroger au péril de faire capoter la virtuosité technique de ce spectacle. Armés chacun d'un Ipad, les vingt spectateurs sont guidés dans une scénographie labyrinthique, et parcourent à travers les yeux de dix protagonistes l'univers mondialisé de l'industrie de l'armement. Ainsi, chacun est tour à tour journaliste au Sud-Soudan, enfant soldat, tireur d'élite, réfugié syrien, pirate informatique, militant pour la paix, chirurgien pour médecin sans frontières, etc. Mécanique rigide et bien huilée, le dispositif scénique tisse ces différents témoignages et superpose trois espaces différents : celui où chaque spectateur évolue et est amené à croiser les autres, endossant des rôles différents, parfois brièvement complémentaires du sien ; celui filmé sur l'Ipad, sorte de double documentaire, dans lequel il aperçoit les vrais protagonistes; et enfin, une vue panoptique de ces espaces, filmée comme une vidéo de surveillance. Le spectateur a constamment l'impression d'être guidé, d'agir à l'aveugle, tout en étant surveillé.

3 S'il y a un constat dressé par Rimini Protokoll sur l'industrie de l'armement, sa mondialisation et ses conséquences, c'est bien celui d'un système bloqué, sur lequel il est difficile d'acquérir une vision d'ensemble. Qu'il soit victime ou bourreau, qu'il encourage ou dénonce la production d'armes et leur circulation, chacun des protagonistes semble avoir ses raisons d'agir ainsi. L'ennemi est absent. Le spectateur change de personnage toutes les sept minutes, entend tour à tour les récits de vie des différents témoins, est amené à regarder un dossier d'enquête, des photos de mutilation de guerre, une vidéo de torture et quelques portraits de famille, et doit se concentrer sur son parcours dans un espace qui devient rapidement labyrinthique. Difficile, après ce spectacle, de conclure à autre chose qu'en la relativité des systèmes de valeur, tant les protagonistes sélectionnés par Rimini Protokoll sont réduits à une fonction. Jamais ils ne sont placés face à leurs contradictions. Jamais le spectateur n'est 
invité à penser la complexité de leurs vécus. Il doit au contraire rentrer de manière superficielle dans leurs existences, sans avoir ni la matière nécessaire à une identification, ni la distance suffisante à une réflexion critique. Tout se passe comme si chacun de ces protagonistes pouvait être réduit à une carte de personnage, à la manière d'un grand jeu de rôle. Comme si les spectateurs ne pouvaient échanger entre eux que des marques anecdotiques de politesse (aider un autre joueur à enlever son manteau, lui serrer la main, le saluer). Un comble pour un spectacle traitant du rapport entretenu par différentes personnes aux armes.

\section{Situation Rooms de Rimini Protokoll}

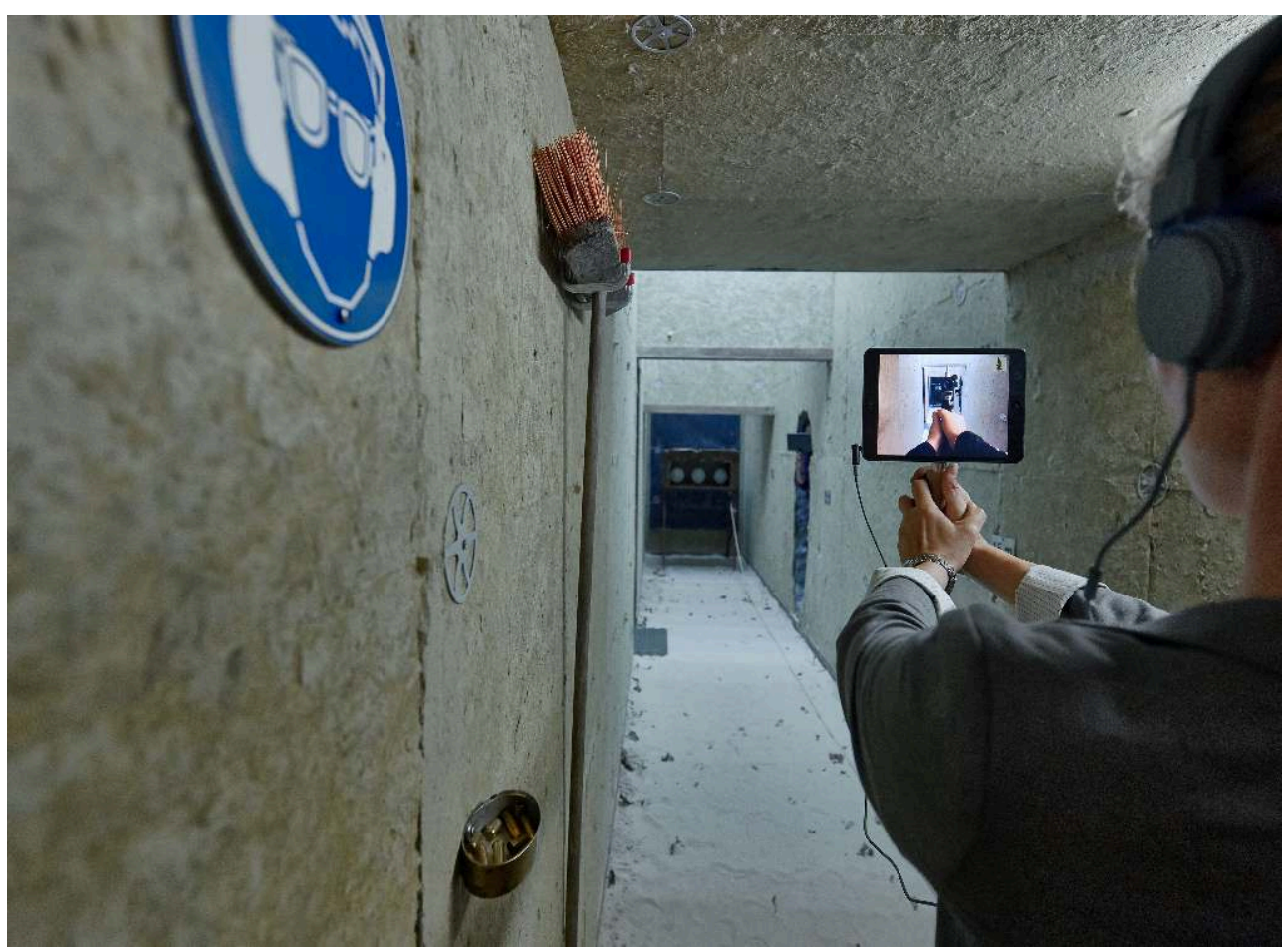

Il semble bien que ce soit cette politesse qui préside à la démarche de Rimini Protokoll. Une politesse qui les aura conduits à rester sur un terrain consensuel avec leurs protagonistes, se contentant de recueillir la version des faits qui ne fâche pas. Il aurait été tellement plus intéressant de saisir l'opportunité de la rencontre de personnes aux parcours aussi opposés, pour faire se confronter leurs différentes versions de la réalité. Alors aurait pu commencer la dispute, autrement dit : la discussion. 